\title{
Erratum: Assessing groundwater recharge in an Andean closed basin using isotopic characterization and a rainfall-runoff model: Salar del Huasco basin, Chile
}

\author{
Javier Uribe ${ }^{1,2} \cdot$ José F. Muñoz ${ }^{2}$ Jorge Gironás ${ }^{2,3,4}$ • Ricardo Oyarzún ${ }^{5,6}$ • \\ ${\text { Evelyn } \text { Aguirre }^{7} \cdot \text { Ramón Aravena }}^{8}$
}

Published online: 1 March 2016

(C) Springer-Verlag Berlin Heidelberg 2016

Erratum to: Hydrogeology Journal (2015) 23: 1535-1551

DOI 10.1007/s10040-015-1300-z

The authors would like to state the following corrections to the published article, due to misunderstandings of the content from two references used in the article.

1) On pages $1544-1545$ it is said that "In particular, and based on the analysis of the salinity and C-14 data, our conceptual model discarded the connection considered by Acosta and
Custodio (2008) between the aquifer of the Salar del Huasco basin and the Pica springs, and thus identified evaporation as the only outflow from the Salar del Huasco basin. Other previous studies support this decision (e.g., Magaritz et al. 1990; Salazar et al. 1998; Tröger and Gerstner 2004)."

This should read as follows "Based on the analysis of the salinity and C-14 data, our conceptual model discarded the connection between the aquifer of the Salar del Huasco basin and the Pica springs, and thus identified evaporation as the

The online version of the original article can be found under doi:10.1007/ s10040-015-1300-z.

Jorge Gironás

jgironas@ing.puc.cl

Geohidrología Consultores Limitada-Arcadis Chile, Antonio Varas 621, Piso 2, Providencia, Santiago, Chile

2 Departamento de Ingeniería Hidráulica y Ambiental, Pontificia Universidad Católica de Chile, Av. Vicuña Mackenna 4860, Macul, Santiago, Chile

3 Centro Interdisciplinario de Cambio Global, Pontificia Universidad Católica de Chile, Av. Vicuña Mackenna 4860, Macul, Santiago, Chile
4 Centro Nacional de Investigación para la Gestión Integrada de Desastres Naturales CONICYT/FONDAP/15110017, Av. Vicuña Mackenna 4860, Macul, Santiago, Chile

5 Departamento Ingeniería de Minas, Universidad de La Serena, Benavente 980, La Serena, Chile

6 Centro de Estudios Avanzados en Zona Áridas (CEAZA), Av. Raúl Bitrán 1305, La Serena, Chile

7 Laboratorio de Isótopos Ambientales, Comisión Chilena de Energía Nuclear, Nueva Bilbao 12501, Las Condes, Santiago, Chile

8 Department of Earth and Environmental Sciences, University of Waterloo, Waterloo, ON, Canada N2L3G1 
Table 4 Long-term average recharge to the aquifer estimated by previous studies

\begin{tabular}{lllll}
\hline Study & $P(\mathrm{~mm} / \mathrm{yr})$ & Min. recharge $(\mathrm{L} / \mathrm{s})$ & Average recharge $(\mathrm{L} / \mathrm{s})$ & Max. recharge $(\mathrm{L} / \mathrm{s})$ \\
\hline DIHA-PUC (2009) & 145.2 & $920(13.8)$ & $1,159(17.3)$ & $1,401(20.9)$ \\
Acosta (2004) & 163.2 & $1,100(13.0)$ & $1,150(13.6)$ & $1,200(14.2)$ \\
\hline
\end{tabular}

only outflow from the Salar del Huasco basin. Other previous studies support this decision (e.g., Magaritz et al. 1990; Salazar et al. 1998; Acosta and Custodio 2008).

2) The original version of Table 4 should be replaced by this new version.

3) On page 1548 it is said that "This range was obtained using the minimum and maximum values of SVR and is more reduced than those estimated from Acosta (2004) and DIHAPUC (2009; Table 4).”
This should read as follows: "This range was obtained using the minimum and maximum values of SVR and is similar to that estimated by Acosta (2004; Table 4), and more reduced than that estimated by DIHA-PUC (2009; Table 4)".

The authors apologize for any inconvenience caused by these misquotations. 